\title{
PENGARUH KOMPENSASI DAN BUDAYA ORGANISASI TERHADAP KINERJA KARYAWAN MELALUI MOTIVASI SEBAGAI VARIABEL INTERVENING PADA PG. KEBON AGUNG
}

\author{
Lutfi Bisri Ashari \\ Mahasiswa Magister Manajemen Pascasarjana Universitas Islam Malang \\ Email: Lutfi234@gmail.com
}

\begin{abstract}
The purpose of this study was to determine the effect of compensation and organizational culture on employee performance through motivation as an intervening variable in PG. Kebon Agung. This study uses quantitative methods. Sampling is done using simple random sampling technique. The samples taken for this study were 88 PG employees PG. Kebon Agung. Data retrieval is done using a questionnaire. The data analysis technique used is path analysis. This study concludes that compensation and organizational culture influence motivation, compensation and organizational culture influence employee performance, motivation influences employee performance and compensation and organizational culture influence employee performance through motivation as an intervening variable.
\end{abstract}

Keywords: Compensation, Organizational Culture, Motivation, Employee Performance, PG. Kebon Agung

\section{PENDAHULUAN}

Dewasa ini perkembangan teknologi semakin pesat yang diikuti oleh berbagai kemajuan di bidang industri atau perusahaan. Perusahaan merupakan sebuah organisasi yang di dalamnya terdiri dari sekelompok orang yang memiliki tujuan yang sama. Perusahaan sebagai sebuah organisasi harus dapat menciptakan budaya organisasi yang baik bagi sumber daya manusia yang dimilikinya. Wibowo (2010:14), yang mengemukakan bahwa "Budaya organisasi adalah sebagai filosofi yang mendasari kebijakan organisasi, aturan main untuk bergaul, dan perasaan atau iklim yang dibawa oleh persiapan fisik organisasi.

Faktor yang mempengaruhi dalam mengatur sebuah budaya organisasi, perusahaan harus bisa mengatur kesejahtraan karyawan salah satunya adalah kompensasi yang di berikan kepada karyawan. Meneurut Gery (2015), kompensasi keryawan adalah semua bentuk pembayaran atau hadiah yang diberikan kepada karyawan dan muncul dari pekerjaan.

Selain mengatur budaya organisasi yang baik di dalam organisasi, sebuah organisasi harus mampu mengelola karyawan dengan baik. Pengelolaan yang baik akan meningkatkan kinerja karyawan. Karyawan yang berkualitas akan menjadikan perusahaan semakin berkembang.

Pabrik Gula Kebon Agung adalah salah satu perusahaan besar yang memproduksi gula dalam skala nasional. Berdasarkan catatan sejarah, PT. PG. Kebonagung berdiri sejak tahun 1905 dan mampu bertahan hingga saat ini. Selain itu PG. Kebon Agung mengalami peningkatan dalam hal kapasitas produksinya yang semula hanya 500 ton tebu per hari, kini menjadi 6000 ton per hari. Perkembangan perusahaan yang baik tidak terlepas dari bagian internal perusahaan yang dimilikinya yaitu karyawan. 
Oleh karena itu faktor sumber daya manusia harus diperhatikan untuk menjaga dan meningkatkan kualitas karyawan.

\section{KAJIAN TEORI \\ Kompensasi}

Menurut Malayu (2013:118), Kompensasi adalah semua pendapatan yang berbentuk uang, barang langsung atau tidak langsung yang diterima karyawan sebagai imbalan atas jasa yang diberikan kepada perusahaan.

Sutrisno (2014:182) mengemukakan bahwa "kompensasi dihitung berdasarkan evaluasi pekerjaan, perhitungan kompensasi berdasarkan evaluasi pekerjaan tersebut dimaksudkan untuk mendapatkan pemberian kompensasi yang mendekati kelayakan (worth) dan keadilan (equity)."

\section{Budaya Organisasi}

Menurut Riani (2011:7) budaya organisasi adalah nilai-nilai, keyakinan dan prinsip-prinsip dasar yang merupakan landasan bagi system dan praktek-praktek manajemen serta perilaku yang meningkatkan dan menguatkan prinsip-prinsip tersebut.

\section{Motivasi}

Mangkunegara (2015:93) mendefinisikan "Motivation as an energizing condition of the organism that serves to direct that organism toward the goal of certain class". (Motivasi sebagai suatu kondisi yang menggerakkan manusia ke arah suatu tujuan tertentu).

Menurut Uno (2008:112) motivasi merupakan suatu dorongan atau proses yang dilakukan untuk menggerakkan seseorang agar perilakunya dapat diarahkan pada suatu tujuan tertentu.

\section{Kinerja Karyawan}

Kinerja merupakan hasil pekerjaan yang sesuai dengan tujuan organisasi, yakni kualitas kerja, kuantitas kerja, efisiensi, dan kriteria efektivitas lainnya Gibson dalam Budaya Organisasi oleh Asri, (2011: 98).

Kinerja menurut Pabundu (2014:121) mengemukakan bahwa kinerja adalah fungsi dari motivasi, kecakapan dan persepsi peranan. 


\section{Kerangka Konseptual}

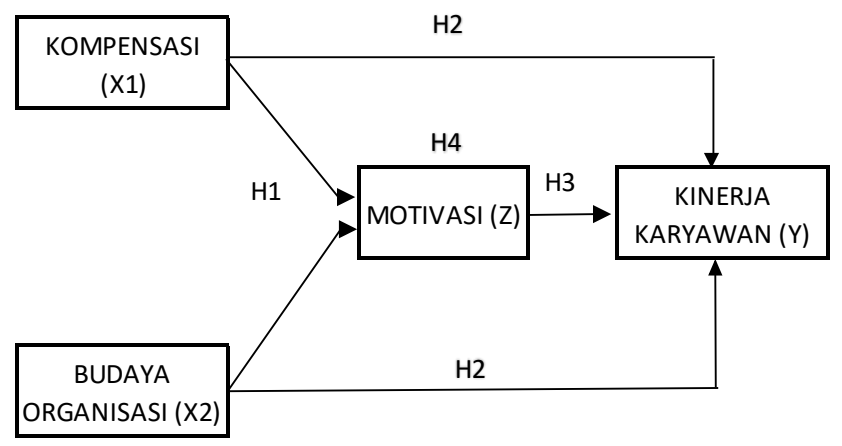

Gambar Kerangka Konseptual

\section{Hipotesis}

Berdasarkan kajian pustaka yang telah diuraikan sebelumnya, maka hipotesis dalam penelitian dapat dirumuskan sebagai berikut:

$\mathrm{H} 1 \quad$ : Kompensasi dan budaya organisasi berpengaruh langsung terhadap motivasi karyawan PG. Kebon Agung.

$\mathrm{H} 2$ : Kompensasi dan budaya organisasi berpengaruh langsung terhadap kinerja karyawan PG. Kebon Agung.

H3 : Motivasi berpengaruh langsung terhadap kinerja karyawan PG. Kebon Agung.

$\mathrm{H} 4$ : Kompensasi dan budaya organisasi berpengaruh tidak langsung terhadap kinerja karyawan melalui motivasi sebagai variabel intervenng pada PG. Kebon Agung.

\section{METODE PENELITIAN \\ Jenis Penelitian}

Berdasarkan rumusan masalah dan tujuan penelitian yang ingin dicapai dalam penelitian ini tergolong dalam jenis penelitian eksplanatori (explanatory research) yaitu penelitian yang bertujuan untuk menguji suatu teori atau hipotesis guna memperkuat atau bahkan menolak teori atau penelitian yang sudah ada.

\section{Lokasi Penelitian}

Penelitian dilakukan di PG. Kebon Agung yang berlokasi di Jalan Raya Kebonagung, Sonosari, Kebonagung Pakisaji Malang.

\section{Waktu Penelitian}

Waktu penelitian kurang lebih berlangsung selama 10 bulan, mulai bulan oktober sampai dengan bulan juli 2019.

\section{Populasi}

Populasi dalam penelitian ini adalah karyawan PG. Kebon Agung yang berlokasi di Jalan Raya Kebonagung, Sonosari, Kebonagung Pakisaji Malang sejumlah 750 orang.

\section{Sampel}


Penentuan jumlah sampel yang digunakan dalam penelitian ini menggunakan rumus Slovin (Sanusi, 2011:101). Adapun rumus yang digunakan yaitu:

$$
n=\frac{n}{1+N e^{2}}
$$

Dimana :

$\mathrm{n}=$ jumlah sampel

$\mathrm{N}=$ jumlah populasi

$\mathrm{e}=$ margin of error, yaitu tingkat kesalahan maksimal pengambilan sampel yang dapat ditoleransi atau bahkan yang diinginkan.

Dengan memakai margin of error sebesar $10 \%$, maka jumlah sampel minimal yang diambil sebeesar 88 responden.

Penelitian ini menggunakan variabel eksogen yaitu kompensasi (X1) dan budaya organisasi $(X)$, variabel endogen yaitu kinerja karyawan $(Y)$ dan variabel intervening yaitu motivasi $(Z)$.

\section{HASIL ANALISIS DATA}

\section{Distribusi Jawaban Responden}

Secara keseluruhan rata-rata jawaban responden pada variabel kompensasi sebesar 4,38.

Secara keseluruhan rata-rata jawaban responden pada variabel budaya organisasi sebesar 4,32.

Secara keseluruhan rata-rata jawaban responden pada variabel motivasi sebesar 4,25.

Secara keseluruhan rata-rata jawaban responden pada variabel kinerja karyawan sebesar 4,33.

\section{Hasil Uji Instrumen Penelitian}

Pengujian validitas istrumen dilakukan dengan cara mengkorelasikan skor item dengan skor total menggunakan teknik KaiserMeyer-Olkin Measure of Sampling Adequacy (KMO-MSA) harus lebih besar dari 0.5. Besarnya angka MSA ialah 0-1. Sehingga variabel tersebut masih dapat diprediksi dan dianalisis lebih lanjut.

\section{Tabel}

Hasil Uji Validitas

\begin{tabular}{|c|c|c|c|}
\hline Variabel bebas & KMO & Nilai Kritis & Keterangan \\
\hline X1 & 0,597 & 0,5 & Valid \\
\hline X2 & 0,617 & 0,6 & Valid \\
\hline Z & 0,644 & 0,7 & Valid \\
\hline Y & 0,666 & 0,8 & Valid \\
\hline
\end{tabular}


Tabel

Hasil Uji Reabilitas

\begin{tabular}{|c|c|c|c|}
\hline No & Variabel & Alpha Cronbach & Keterangan \\
\hline 1 & Kompensasi (X1) & 0,606 & Reliabel \\
\hline 2 & Budaya Organisasi (X2) & 0,642 & Reliabel \\
\hline 3 & Motivasi (Z) & 0,639 & Reliabel \\
\hline 4 & Kinerja Karyawan (Y) & 0,621 & Reliabel \\
\hline
\end{tabular}

Sumber : Data diolah, 2019.

Instrument dikatakan reliabel, jika nilai Crobach's Alpha $<0,6$ berdasarkan tabel di atas diketahui bahwa nilai alpha crobach's pada variabel independen berada di atas 0,6 sehingga dapat disimpulkan bahwa variabel tersebut telah reliable dan dapat dilakukan analisis selanjutnya.

\section{Uji Normalitas}

Tabel

One-Sample Kolmogorov-Smirnov Test

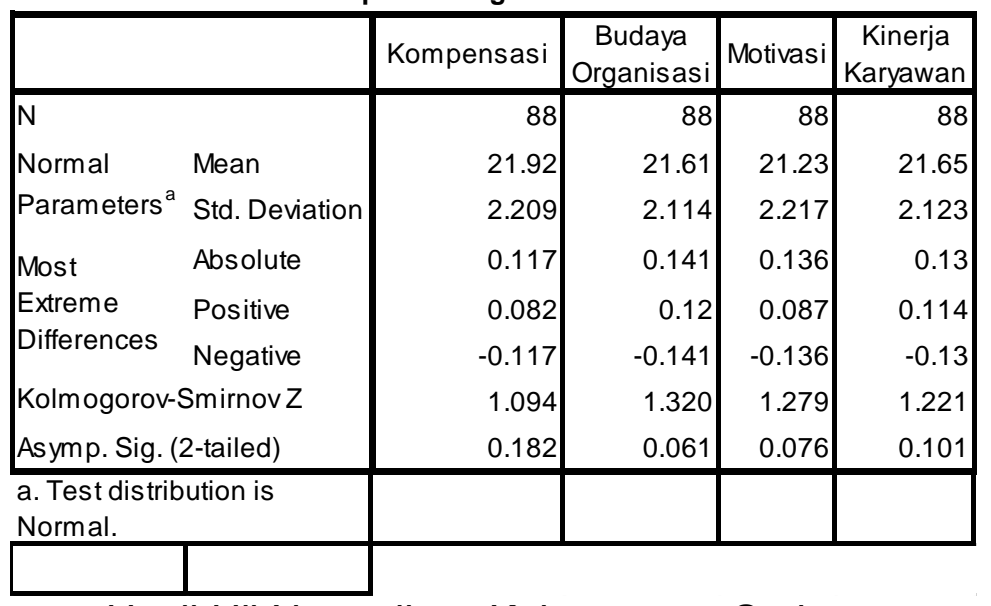

Hasil Uji Normalitas Kolmogorov_Smirnov

Berdasarkan tabel diatas terlihat bahwa nilai signifikansi residual regresi yang terbentuk lebih besar dari taraf nyata $5 \%$ sehingga dapat dikatakan bahwa asumsi normalitas tersebut terpenuhi. 


\section{Analisis Jalur (Path Analysis)}

\section{Model path 1 variabel kompensasi dan budaya organisasi terhadap} motivasi

Tabel

Hasil regresi linier berganda

\begin{tabular}{|ll|r|r|r|}
\hline \multicolumn{2}{|c|}{ Coefficients $^{\mathrm{a}}$} \\
\multicolumn{2}{|l|}{ Model } & \multicolumn{2}{|c|}{$\begin{array}{c}\text { Unstandardized } \\
\text { Coefficients }\end{array}$} & \multicolumn{2}{c|}{$\begin{array}{c}\text { Standardized } \\
\text { Coefficients }\end{array}$} \\
\cline { 2 - 5 } & \multicolumn{1}{|c|}{ B } & Std. Error & \multicolumn{1}{c|}{ Beta } \\
\hline \multirow{2}{*}{1 (Constant) } & 0.26 & 1.084 & \\
& Kompensasi & 0.556 & 0.086 & 0.554 \\
& Budaya Organisasi & 0.407 & 0.09 & 0.388 \\
\hline
\end{tabular}

a. Dependent Variable: Motivasi

Persamaan model satu pada tabel di atas adalah sebagai berikut:

$Z=0,554 X_{1}+0,388 X_{2}$

Hasil persamaan besar pengaruh $\mathrm{X} 1$ dan $\mathrm{X} 2$ terhadap $\mathrm{Z}$ adalah:

1. $\beta_{1}$ (nilai koefisien $X_{1}$ ) 0,554 mempunyai arti bahwa kompensasi berpengaruh positif terhadap motivasi.

2. $\beta_{2}$ (nilai koefisien $X_{2}$ ) 0,388 mempunyai arti bahwa budaya organisasi berpengaruh positif terhadap motivasi.

\section{Model path 2 variabel kompensasi dan budaya organisasi terhadap kinerja karyawan}

Tabel

Hasil regresi linier berganda

Coefficients $^{a}$

\begin{tabular}{|ll|r|r|r|}
\hline \multirow{2}{*}{ Model } & \multicolumn{2}{|c|}{$\begin{array}{c}\text { Unstandardized } \\
\text { Coefficients }\end{array}$} & \multicolumn{2}{|c|}{$\begin{array}{c}\text { Standardized } \\
\text { Coefficients }\end{array}$} \\
\cline { 2 - 5 } & \multicolumn{1}{|c|}{ B } & Std. Error & \multicolumn{2}{|c|}{ Beta } \\
\hline \multirow{2}{*}{1.253} & 0.983 & & 0.312 \\
(Constant) & Kompensasi & 0.3 & 0.078 & 0.637 \\
\hline
\end{tabular}

a. Dependent Variable: Kinerja Karyawan

Persamaan model kedua pada tabel di atas adalah sebagai berikut:

$Y=0,312 X_{1}+0,637 X_{2}$

Hasil persamaan besar pengaruh $\mathrm{X} 1$ dan $\mathrm{X} 2$ terhadap $\mathrm{Y}$ adalah:

1. $\beta_{3}$ (nilai koefisien $X_{1}$ ) 0,312 mempunyai arti bahwa kompensasi berpengaruh positif terhadap kinerja karyawan.

2. $\beta_{4}$ (nilai koefisien $X_{2}$ ) 0,637 mempunyai arti bahwa budaya organisasi berpengaruh positif terhadap kinerja karyawan. 
Model path 3 variabel motivasi terhadap kinerja karyawan

Tabel

Hasil regresi linier berganda

Coefficients $^{a}$

\begin{tabular}{|c|r|r|r|}
\hline \multirow{2}{*}{ Model } & \multicolumn{2}{|c|}{$\begin{array}{c}\text { Unstandardized } \\
\text { Coefficients }\end{array}$} & \multicolumn{2}{|c|}{$\begin{array}{c}\text { Standardized } \\
\text { Coefficients }\end{array}$} \\
\cline { 2 - 5 } & \multicolumn{1}{|c|}{$\mathrm{B}$} & \multicolumn{1}{c|}{ Std. Error } & \multicolumn{1}{c|}{ Beta } \\
\hline \multirow{2}{*}{1 (Constant) } & 3.321 & 0.954 & \\
Motivasi & 0.863 & 0.045 & 0.901 \\
\hline
\end{tabular}

a. Dependent Variable: Kinerja Karyawan

Persamaan model ketiga pada tabel di atas adalah sebagai berikut:

$\mathrm{Y}=0,901 \mathrm{Z}$

Hasil persamaan besar pengaruh $Z$ terhadap $Y$ adalah:

$\beta_{5}$ (nilai koefisien $X_{1}$ ) 0,901 mempunyai arti bahwa Motivasi berpengaruh positif terhadap kinerja karyawan.

Model 4 Path Analysis Pengaruh Kompensasi (X1) dan Budaya Organisasi (X2) melalui Motivasi (Z) terhadap Kinerja Karyawan (Y)

Tabel

Hasil Path Analysis Model 4

\begin{tabular}{|c|c|c|c|}
\hline \multicolumn{4}{|c|}{ Coefficients $^{\mathrm{a}}$} \\
\hline \multirow{2}{*}{ Model } & \multicolumn{2}{|c|}{$\begin{array}{l}\text { Unstandardized } \\
\text { Coefficients }\end{array}$} & \multirow{2}{*}{$\begin{array}{c}\begin{array}{c}\text { Standardized } \\
\text { Coefficients }\end{array} \\
\text { Beta }\end{array}$} \\
\hline & B & Std. Error & \\
\hline (Constant) & 1.253 & 0.983 & \\
\hline 1 Kompensasi & 0.3 & 0.078 & 0.312 \\
\hline Budaya Organisasi & 0.64 & 0.081 & 0.637 \\
\hline \multicolumn{4}{|c|}{ a. Dependent Variable: Kinerja Karyawan } \\
\hline \multicolumn{4}{|c|}{ Coefficients $^{a}$} \\
\hline \multirow{2}{*}{ Model } & \multicolumn{2}{|c|}{$\begin{array}{l}\text { Unstandardized } \\
\text { Coefficients }\end{array}$} & $\begin{array}{c}\text { Standardized } \\
\text { Coefficients }\end{array}$ \\
\hline & B & Std. Error & Beta \\
\hline (Constant) & 3.321 & 0.954 & \\
\hline Motivasi & 0.863 & 0.045 & 0.901 \\
\hline
\end{tabular}

Hasil data path analysis model 4 yang tampak pada tabel 4.17 diperoleh nilai bilai beta variabel Kompensasi sebesar 0,312 merupakan nilai $X_{1}$ terhadap $Y$ melalui $Z$ sebesar 0,901 . Nilai beta variabel Budaya Organisasi sebesar $0,637 X_{2}$ terhadap $Y$ melalui $Z$ sebesar 0,901 .

$Y=\left(\beta_{1} \cdot \beta_{7}\right)+\left(\beta_{2} \cdot \beta_{7}\right)+\left(\beta_{3} . \beta_{7}\right)$ atau $Y=(0,312 \times 0,901)+$ $(0,637 \times 0,901)$

Keterangan :

$\mathrm{X}_{1}=$ Kompensasi

$\mathrm{X}_{2}=$ Budaya Organisasi

$Z$ = Motivasi

$\mathrm{Y}=$ Kinerja Karyawan

Hasil data path analysis diatas memberikan pengertian bahwa $\beta_{1}$ (nilai koefisien beta $X_{1}$ ) 0,312 memiliki pengertian bahwa Kompensasi mempunyai pengaruh positif terhadap Kinerja Karyawan, jika Kompensasi semakin ditingkatkan maka Kinerja Karyawan karyawan akan meningkat. 
$\beta_{2}$ (nilai koefisien beta $X_{2}$ ) 0,637 mempunyai arti bahwa Budaya Organisasi mempunyai pengaruh positif terhadap Kinerja Karyawan, jika Budaya Organisasi semakin ditingkatkan, maka Kinerja Karyawan karyawan juga akan meningkat. $\beta_{7}$ (nilai koefisien beta Z) 0,901 memiliki pengertian bahwa Motivasi mempunyai pengaruh positif terhadap Kinerja Karyawan, jika Motivasi karyawan meningkat maka Kinerja Karyawan karyawan juga akan meningkat.

\section{Uji t}

Tabel

Hasil Uji t

\begin{tabular}{|c|c|c|c|}
\hline \multicolumn{4}{|c|}{ Kompensasi dan budaya organisasi terhadap motivasi } \\
\hline Model & & $t$ & Sig. \\
\hline \multirow{3}{*}{1} & (Constant) & 0.24 & 0.811 \\
\hline & Kompensasi & 6.485 & 0.000 \\
\hline & Budaya Organisasi & 4.541 & 0.000 \\
\hline \multicolumn{4}{|c|}{ Kompensasi dan budaya organisasi terhadap Kinerja Karyawan } \\
\hline \multicolumn{2}{|l|}{ Model } & $\mathrm{t}$ & Sig. \\
\hline \multirow{3}{*}{2} & (Constant) & 1.275 & 0.206 \\
\hline & Kompensasi & 3.862 & 0.000 \\
\hline & Budaya Organisasi & 7.885 & 0.000 \\
\hline \multicolumn{4}{|c|}{ Motivasi terhadap Kinerja Karyawan } \\
\hline \multicolumn{2}{|l|}{ Model } & $\mathrm{t}$ & Sig. \\
\hline \multirow{3}{*}{3} & (Constant) & 1.275 & 0.206 \\
\hline & Kompensasi & 3.862 & 0.000 \\
\hline & Budaya Organisasi & 7.885 & 0.000 \\
\hline
\end{tabular}

1. Pengaruh kompensasi dan budaya organisasi terhadap motivasi

a. Pengaruh variabel kompensasi terhadap motivasi diperoleh nilai thitung $>t_{\text {tabel }}(6,485>1,987)$ dan singinifikansi $0.000<0.05$. maka $\mathrm{H} 1$ Kompensasi diterima, yang berarti ada pengaruh secara signifikansi kompensasi terhadap motivasi pada PG Kebon Agung.

b. Pengaruh variabel budaya organisasi terhadap motivasi diperoleh nilai $t_{\text {hitung }}>t_{\text {tabel }}(4,541>1.987)$ dan singinifikansi $0.000<0.05$. maka $\mathrm{H} 1$ budaya organisasi diterima, yang berarti ada pengaruh secara signifikansi variabel budaya organisasi terhadap variabel motivasi pada PG Kebon Agung.

2. Pengaruh kompensasi dan budaya organisasi terhadap kinerja karyawan

a. Pengaruh variabel kompensasi terhadap kinerja karyawan diperoleh nilai $t_{\text {hitung }}>t_{\text {tabel }}(3,862>1.987)$ dan singinifikansi $0.000>0.05$. maka H2 Kompensasi diterima, yang berarti ada pengaruh secara signifikansi variabel kompensasi terhadap kinerja karyawan pada PG Kebon Agung.

b. Pengaruh variabel budaya organisasi terhadap kinerja karyawan diperoleh nilai thitung $>t_{\text {tabel }}(7,885>1.987)$ dan singinifikansi $0.000>$ 0.05. maka $\mathrm{H} 2$ budaya organisasi diterima, yang berarti ada pengaruh secara signifikansi Variabel budaya organisasi terhadap kinerja karyawan pada PG Kebon Agung.

3. Pengaruh motivasi terhadap kinerja karyawan 
Pengaruh variabel motivasi terhadap kinerja karyawan diperoleh nilai $t_{\text {hitung }}>t_{\text {tabel }}(19,313>1.987)$ dan singinifikansi $0.000<0.05$. maka H3 diterima, yang berarti ada pengaruh secara signifikansi Variabel motivasi terhadap kinerja karyawan pada pada PG Kebon Agung.

\section{Uji Sobel danielsoper}

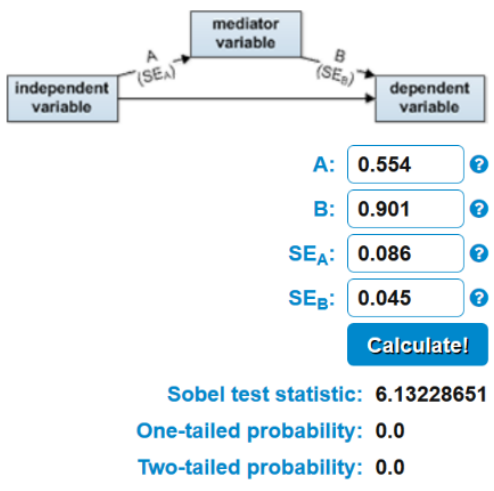

Gambar

Uji Sobel Test Model 1

Berdasarkan gambar diatas menunjukkan hasil one-talled probabilty sebesar $0,00<0,05$, sehingga dapat disimpulkan variabel motivasi dapat memediasi variabel kompensasi terhadap kinerja karyawan.

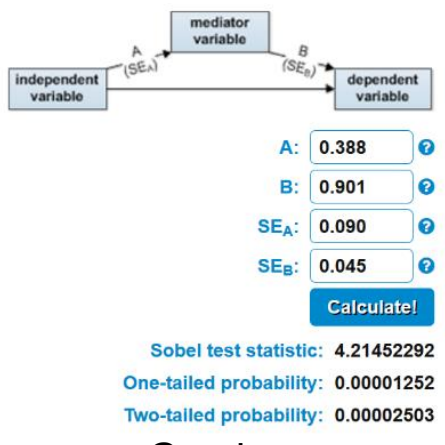

Gambar

Uji Sobel Test Model 2

Berdasarkan gambar diatas menunjukkan hasil one-talled probabilty sebesar 0,00001252<0,05, sehingga dapat disimpulkan variabel motivasi dapat memediasi variabel budaya organisasi terhadap kinerja karyawan.

\section{Goodness of fit Model}

Tabel

Goodness of fit model

\begin{tabular}{|c|c|}
\hline Variabel & $\mathrm{R}^{2}$ \\
\hline Motivasi $(\mathrm{Z})$ & 0.818 \\
\hline Kinerja Karyawan $(\mathrm{Y})$ & 0.837 \\
\hline$R_{m}^{2}=1-\left(\left(1-R_{Y 1}^{2}\right)^{*}\left(1-R_{Y 2}^{2}\right)\right)$ & \\
$R_{m}^{2}=1-\left((1-0.818)^{*}(1-0.837)\right)=0.970$ & \\
\hline
\end{tabular}


$\mathrm{R}^{2}$ Square variabel motivasi berniali 0.818 atau $81,8 \%$. hal ini dapat menunjukan bahwa motivasi mampu dijelaskan oleh kompensasi dan budaya organisasi sebesar $81,8 \%$ atau dengan kata lain konstribusi kompensasi dan budaya organisasi sebesar $81,8 \%$. sedangkan sisanya sebesar 18,9\% merupakan kostribusi variabel lain yang tidak dibahas dalam penelitian ini.

Sedangkan $\mathrm{R}^{2}$ Square variabel kinerja karyawan berniali 0.837 atau $83,7 \%$. hal ini dapat menunjukan bahwa kinerja karyawan mampu dijelaskan oleh kompensasi, budaya organisasi dan motivasi sebesar $83,7 \%$, atau dengan kata lain konstribusi kompensasi, budaya organisasi dan motivasi sebesar $83,7 \%$, sedangkan sisanya sebesar $16,3 \%$ merupakan konstribusi variabel lain yang tidak dibahas dalam penelitian ini.

Koefisien determinasi total $\left(\mathrm{R}_{\mathrm{m}}{ }^{2}\right)$ bernilai 0,970 atau $97 \%$. hal ini dapat disimpulkan bahwa keragaman kinerja karyawan dan motivasi mampu dijelaskan oleh model secara keselurruhan sebesar $97 \%$, atau dengan kata lain konstribusi kompensasi, budaya organisasi terhadap kinerja karyawan dan motivasi sebesar $97 \%$, sedangkan sisanya $3 \%$ merupakan konstribusi variabel lain yang tidak dibahas dalam penelitian ini.

\section{Hasil Rekap Total Pengaruh Langsung dan Tidak Langsung}

Tabel

Hasil Rekap Total Pengaruh Langsung dan Tidak Langsung

\begin{tabular}{|c|c|c|c|c|c|c|}
\hline \multirow{2}{*}{ No. } & \multirow{2}{*}{ Pengaruh Variabel } & \multicolumn{3}{|c|}{ Pengaruh Kausal } & \multirow{2}{*}{ Total } & \multirow{2}{*}{ Sig. } \\
\hline & & Langsung & Tidak Langsung & total Effect & & \\
\hline \multirow[b]{2}{*}{1} & \multirow{2}{*}{$\begin{array}{l}\text { Kompensasi }\left(\mathrm{X}_{1}\right) \text {, Budaya } \\
\text { Organisasi }\left(\mathrm{X}_{2}\right) \text { terhadap Motivasi } \\
(\mathrm{Z})\end{array}$} & $\beta 1=0,554$ & & & 0,554 & 0,000 \\
\hline & & $\beta 2=0,388$ & & & 0,388 & 0,000 \\
\hline \multirow{2}{*}{2} & \multirow{2}{*}{$\begin{array}{l}\text { Kompensasi }\left(\mathrm{X}_{1}\right) \text {, Budaya } \\
\text { Organisasi }\left(\mathrm{X}_{2}\right) \text { terhadap Kinerja } \\
\text { Karyawan }(\mathrm{Y}) \\
\end{array}$} & $\beta 3=0,312$ & & & 0,312 & 0,000 \\
\hline & & $\beta 4=0,637$ & & & 0,637 & 0,000 \\
\hline 3 & $\begin{array}{l}\text { Motivasi (Z) terhadap Kinerja } \\
\text { Karyawan }(Y)\end{array}$ & $\beta 5=0,901$ & & & 0,901 & 0,000 \\
\hline \multirow{2}{*}{4} & \multirow{2}{*}{$\begin{array}{l}\text { Kompensasi }\left(\mathrm{X}_{1}\right) \text {, Budaya } \\
\text { Organisasi }\left(\mathrm{X}_{2}\right) \text { terhadap Kinerja } \\
\text { Karyawan }(\mathrm{Y}) \text { melalui Motivasi }(\mathrm{Z})\end{array}$} & & $\begin{array}{l}\beta_{1 \times} \beta_{5}=0,554 \times 0,901= \\
0,499\end{array}$ & $\beta_{3}=0,312$ & 0,811 & 0,000 \\
\hline & & & $\begin{array}{l}\beta_{1 \times} \beta_{5=}=0,388 \times 0,901= \\
0,350\end{array}$ & $\beta_{4}=0,637$ & 0,988 & 0,000 \\
\hline & Total & 2,792 & 0,849 & 0,949 & 4,591 & 0,000 \\
\hline
\end{tabular}

Hasil data path analysis yang tampak pada tabel di atas diperoleh nilai beta:

1. Kompensasi $\left(X_{1}\right)$, Budaya Organisasi $\left(X_{2}\right)$ terhadap Motivasi $(Z)$

a).Pengaruh Kompensasi $\left(X_{1}\right)$, terhadap Motivasi $(Z)$ sebesar 0,554

b).Pengaruh Budaya Organisasi $\left(X_{2}\right)$ terhadap Motivasi $(Z)$ sebesar 0,388

2. Kompensasi $\left(X_{1}\right)$, Budaya Organisasi $\left(X_{2}\right)$ terhadap Kinerja Karyawan $(\mathrm{Y})$ 


\section{PEMBAHASAN}

\section{Kompensasi dan Budaya Organisasi terhadap Motivasi}

\section{a. Kompensasi terhadap Motivasi}

Hasil penelitian ini menunjukan bahwa kompensasi berpengaruh positif dan signifikan terhadap variabel motivasi. Semakin baik kompensasi maka karyawan akan termotivasi dan kinerja perusahaan akan menjadi meningkat. Koefisien pengaruh langsung kompensasi terhadap motivasi sebesar 0.554 atau 55,4\%.

Hasil penelitian ini didukung oleh penelitian serupa yang dilakukan oleh Graha dan Rahardjo (2016) menunjukkan bahwa kompensasi berpengaruh positif terhadap motivasi.

Terdapat beberapa hal yang dilakukan oleh Manajer PG Kebon Agung Malang dalam rangka meningkatkan MSDM yaitu dengan memberikan kompensasi langsung maupun tidak langsung seperti bonus, tunjangan, insentif, fasilitas dengan melihat kinerja karyawan Dengan begitu karyawan akan termotivasi untuk bekerja dengan baik.

\section{b. Pengaruh Budaya Organisasi terhadap Motivasi}

Hasil penelitian ini menunjukan bahwa budaya organisasi berpengaruh positif dan signifikan terhadap motivasi dengan hasil koefisien pengaruh budaya organisasi terhadap motivasi sebesar 0.388 atau 38,8\%.

Hasil penelitian ini didukung oleh penelitian serupa yang dilakukan oleh Haqq dapat disimpulkan bahwa budaya organisasi memiliki pengaruh positif dan signifikan terhadap motivasi.

Manajer PG Kebon Agung dalam rangka meningkatkan MSDM perusahaan. Manajer berperan aktif dalam mengatur dan membentuk budaya organisasi di PG Kebon Agung, di antaranya adalah mengatur waktu, berfikir positif, komunikasi dan lain-lain dalam membentuk budaya organisasi.

\section{Kompensasi dan Budaya Organisasi terhadap Kinerja Karyawan a. Kompensasi terhadap Kinerja Karyawan}

Hasil penelitian ini menunjukan bahwa kompensasi berpengaruh positif dan signifikan terhadap kinerja karyawan. Hasil koefisiensi pengaruh langsung kompensasi terhadap kinerja ka -...- n sebesar 0.312 atau setara dengan 31,2\%. Hal ini menunjuke 91 ınwa kompensasi dapat meningkatkan kinerja karyawan dalam suau pekerjaan. Semakin baik kompensasi maka akan semakin baik pula kinerja karyawan.

Hasil penelitian ini didukung oleh penelitian serupa yang dilakukan oleh Graha dan Rahardjo (2016) dengan hasil bahwa kompensasi berpengaruh positif terhadap kinerja karyawan.

Pemberian kompensasi yang sesuai dapat menjadikan karyawan lebih baik dalam melakukan pekerjaannya. Karyawan tidak akan melakukan keberatan ketika mengerjakan suatu pekerjaan karena tenaga dan pikiran yang digunakan sebanding dengan hasil yang didapatkan. Hal tersebut yang dilakukan oleh pihak PG. Kebon Agung kepada karyawannya.

\section{b. Pengaruh Budaya Organisasi terhadap Kinerja Karyawan}


Hasil penelitian ini menunjukan bahwa budaya organisasi berpengaruh positif dan signifikan terhadap kinerja karyawan. Semakin baik perusahaan bisa mengatur budaya organisasi maka kinerja karyawan akan meningkat dalam sebuah pekerjaan. Hasil dari perhitungan dalam penelitian ini menunjukan bahwa koefisiensi pengaruh langsung budaya organisasi terhadap kinerja karyawan sebesar 0,637 atau 63,7\%.

Hasil penelitian ini didukung oleh penelitian serupa yang dilakukan oleh Haqq (2016) yang menyatakan bahawa terdapat pengaruh positif dan signifikan budaya organisasi terhadap kinerja karyawan.

PG Kebon Agung memiliki budaya organisai yang baik. Diantaranya adalah keramahan yang dipraktikkan antar karyawan. Baik antara atasan dan bawahan maupun dengan sesama karyawan. Selain itu terdapat budaya untuk mengerjakan pekerjaan secara tepat waktu. Team work juga berjalan dengan baik yang didukung dengan komunikasi yang baik pula.

\section{Pengaruh Motivasi terhadap kinerja karyawan}

Hasil penelitian ini menunjukan bahwa motivasi berpengaruh positif dan signifikan terhadap kinerja karyawan. Semakin baik perusahaan bisa mengatur motivasi maka kinerja karyawan akan meningkat dalam sebuah pekerjaan. Hasil perhitungan data dalam penelitian ini menunjukan bahwa koefisiensi pengaruh langsung motivasi terhadap kinerja karyawan sebesar 0,901 atau setara dengan $90,1 \%$.

Hasil penelitian ini didukung oleh penelitian serupa yang dilakukan oleh Haqq (2016) yang menyatakan bahwa terdapat pengaruh positif dan signifikan motivasi terhadap kinerja karyawan.

\section{Kompensasi dan Budaya Organisasi terhadap Kinerja Karyawan Melalui Motivasi}

\section{a. Kompensasi terhadap Kinerja Karyawan Melalui Motivasi}

Koefisien pengaruh tidak langsung kompensasi terhadap kinerja karyawan melalui motivasi sebesar 0,811 atau $81,1 \%$. hal ini menunjukan bahwa kompensasi berpengaruh positif dan signifikansi terhadap kinerja melalui motivasi. Dapat diartikan disini bahwa semakin baik kompensasi untuk karyawan makan karyawan akan termotivasi dan kinerja karyawan akan semakin baik.

Dan untuk uji sobel danielsoper hasil one-talled probabilty sebesar $0,00<0,05$, sehingga dapat disimpulkan variabel kepuasan pelanggan dapat memediasi variabel harga terhadap loyalitas pelanggan.

Menunjukan bahwa kompensasi terhadap kinerja karyawan berpengaruh secara signifikan melalui motivasi dengan tidak di dukung oleh penelitian terdahulu oleh shalahudin (2014) dalam penelitian "pengaruh kompensasi dan budaya organisasi terhadap kinerja pegawai melalui motivasi sebagai variabel intervening".

\section{b. Budaya Organisasi terhadap Kinerja Karyawan Melalui Motivasi}

Koefisien pengaruh tidak langsung budaya organisasi terhadap kinerja karyawan melalui motivasi sebesar 0,988 aatau $98,8 \%$. hal ini menunjukan bahwa budaya organisasi berpengaruh positif dan signifikansi terhadap kinerja karyawan melalui motvasi. Dapat diartikan disini bahwa 
semakin baik budaya oragnisasi di dalam perusahaan maka akan membantu karyawan termotivasi dan kinerja karyawan akan sangat baik.

Dan untuk uji sobel danielsoper hasil one-talled probabilty sebesar $0,00001252<0,05$, sehingga dapat disimpulkan variabel kepuasan pelanggan dapat memediasi variabel kualitas produk terhadap loyalitas pelanggan.

Menunjukan bahwa budaya organisasi berpengaruh secara signifikan terhadap kinerja karywan melalui motivasi sebagai variabel intervening yang didukung oleh penelitian terdahulu oleh salahudin (2014) dalam penelitian "pengaruh kompensasi dan budaya organisasi terhadap kinerja pegawai melalui motivasi sebagai variabel intervening" dan haqq (2016) dalam penelitian "pengaruh budaya organisasi terhadap kinerja karyawan melalui motivasi sebagai variabel intervening studi pada PT. Rahmat Jaya Perkasa Sidoarjo".

\section{SIMPULAN DAN SARAN}

Penelitian ini bertujuan untuk mengetahui pengaruh langsung dan tidak langsungnya variabel kompensasi dan budaya organisasi terhadap kinerja karyawan melalui motivasi sebagai variabel intervening. Pengambilan data dilakukan menggunakan kuesioner dengan jumlah sampel sebanyak 88 karyawan PG. Kebon Agung Malang. Adapun hasil penelitian diperoleh sebagai berikut:

1. Kompensasi dan budaya organisasi berpengaruh signifikan terhadap motivasi.

2. Kompensasi dan budaya organisasi berpengaruh signifikan terhadap kinerja karyawan.

3. Motivasi berpengaruh signifikan terhadap kinerja karyawan.

4. Kompensasi dan budaya organisasi berpengaruh signifikan terhadap kinerja karyawan melalui motivasi.

Berdasarkan hasil penelitian dapat disimpulkan bahwa kompensasi dan budaya organisasi berpengaruh tidak langsung secara signifikan terhadap kinerja karyawan melalui motivasi sebagai variabel intervening.

Berdasarkan hasil penelitian yang telah dikemukakan diatas, maka saran yang dapat direkomendasikan untuk menjdai pertimbangan bagi penelitian selanjutnya adalah sebagai berikut:

a. Melakukan penelitian diluar variabel bebas yang mempengaruhi kinerja karyawan yang digunakan dalam penelitian ini yaitu kompensasi dan budaya organisasi.

b. Bagi penelitian selanjutnya, disarankan untuk bisa mengidentifikasi dan mendeskripsikan lebih luas tentang responden yang digunakan dalam penelitian ini selain yang dijabarkan oleh peneliti.

\section{DAFTAR PUSTAKA}

Arep, Ishak dan Hendri Tanjung. 2003. Manajemen Sumber Daya Manusia. Universitas Trisakti: Jakarta.

Arikunto, Suharsii. 2001. Prosedur Penelitian Suatu Pendekatan Prakter. Bina Aksara: Jakarta. 
Anoraga, Panji \& Ninik Widiyanti. 2013. Psikologi Dalam Perusahaan. Rineka Cipta: Jakarta.

Bangun, Wilson. 2012. Manajemen Sumber Daya Manusia, Erlangga. Bandung:

Desseler, Gery. 2015. Manajemen Sumber Daya Manusia (Edisi Empat Belas), Salemba Empat: Jakarta.

Ernie Tisnawati Sule \& Kurniawan Saefullah. 2015. Pengantar Manajemen. Kencana Prenada Media Goup: Jakarta.

Edy Sutrisno,.2012. Manajemen Sumber Daya Manusia. Kencana Prenada media Group: Jakarta.

Ghozali, Imam. 2006. Aplikasi Analisis Multivariate dengan Program IBM SPSS. Badan Penerbit Unibersitas Diponegoro: Semarang. . 2007. Aplikasi Analisis Multivariant dengan Program IMB SPSS 19. UNDIP: semarang. 2009. Aplikasi Analisis Multivariant dengan Program IMB SPSS 19. UNDIP: Semarang. . 2011. Aplikasi Analisis Multivariant dengan Program IMB SPSS 19. UNDIP: Semarang.

.2013. Manajemen Sumber Daya Manusia. Kencana Prenada media Group: Jakarta

Gibson, james, J dan Ivancevich, N J. Donnely. 2011. Organisasi, perilaku, struktur dan proses. Binarupa Aksara: Jakarta.

Graha, Alexander Monte Christo Arta dan Rahardjo, Edy. 2016. Analisis Pengaruh Budaya Organisasi dan Kompensasi terhadap Kinerja Karyawan dengan Motivasi sebagai Variabel Intervening (Studi Kasus pada PT. LG Bagian Penjualan Indonesia Semarang). Jurnal Studi Manajemen dan Organisasi 13 (2016) Desember 98-109

Hammed, A., Ramzan, M., Zubair, H.M.K, Ali G dan Arslan, M (2014). Impact of Compensation on Employee Performance (Empirical Evidence from Bangking Sector of Pakistan). International Journal of Business and Social Science, Vol. 5, No. 2, pp.302-309

Hasibuan S.P..2000. Organisasi dan Motivasi. Bumi Aksara: Jakarta. .2010. Manajemen Sumber Daya Manusia. Bumi Aksara: Jakarta. Jakarta.

2012. Manajemen Sı 101 Daya Manusia. Bumi Aksara: 2013. Manajemen Sumber Daya Manusia. Bumi Aksara: Jakarta.

Haqq, Najmi. 2016. Pengaruh Budaya Organisasi terhadap Kinerja Karyawan Melalui Motivasi sebagai Variabel Intervening Studi pada PT. Rahmat Jaya Perkasa Sidoarjo. Jurnal Bisnis dan Manajemen. Volume 9 No. 1 Oktober 2016

Ismainar, hetty. 2015. Manajemen Unit Kerja. Deepublish: Jogjakarta.

Juanim. 2004. Analisis Jalur dalam Riset Pemasaran. Universitas Pasundan, Bandung.

Juliningrum, Emmy dan Sudiro, Achmad. 2013. Pengaruh Kompensasi, Budaya Organisasi terhadap Kompensasi dan Kinerja Pegawai. 
Jonathan, Sarwono. 2006. Metode Penelitian Kuantitatif dan Kualitatif. Graha IImu: Yogyakarta.

Kadarisman. 2014. Manajemen Kompensasi. Rajawali Pers Malayu: Jakarta.

Mangkunegara, Anwar Prabu. 2005. Manajemen Sumber Daya Manusia. Cetakan keenam penerbit PT. Remaja Rosdakarya. Bandung. .2009. Evaluasi Kinerja SDM. Refika Aditama: Jakarta. .2015. Evaluasi Kinerja Sumber Daya Manusia. Penerbit Refika Aditama: Bandung. .2015. Sumber Daya Manusia Perusahaan. Cetakan Kedua belas. Remaja Rosdakarya: Bandung.

Mathis dan Jackson. 2009. Manajemen Sumber Daya Manusia. Edisi 10. Salemba Empat: Jakarta.

Marwansyah. 2014. Manajemen Sumber Daya Manusia. Edisi Kedua. Alfabeta: Bandung

Masri Singarimbun \& Sofyan Effendi, 1995, Metode Penelitian Survei, Edisi Revisi, PT. Pustaka LP3ES: Jakarta

Nazir, Dr. Shazia Zamir Nadia, Najmi. 2015. Impact of Organizational Culture on Employee's Performance. National University of Modern Languages, Islamabad, Industrial Engineering Letters Vol.5, No.9, 2015

Nurcahyani, Ni Made dan Adnyani, I.G.A Dewi. 2016. Pengaruh Kompensasi dan Motivasi terhadap Kinerja Karyawan dengan Kepuasan Kerja sebagai Variabel Intervening. E-Jurnal Manajemen Unud, Vol. 5, No. 1, 2016:500-532

Nugroho, Agus Dwi dan Kunartinah. 2012. Analisis Pengaruh Kompensasi dan Pengembangan Kaier terhadap Kepuasan Kerja dengan Mediasi Motivasi Kerja. Jurnal Bisnis dan Ekonomi. Vol.19, No.2.

Pabundu Tika. 2014. Budaya Organisasi dan Peningkatan Kinerja Perusahaan. Cetakan Kelima. PT. Bumi Aksara: Jakarta.

Riani, Asri Laksmi.2011.Budaya Organisasi, Cetakan Pertama, Graha Ilmu: Yogyakarta.

Riduwan dan Engkos Achmad Kuncoro. 2014. Analisis Jalur. Cetakan Ke enam. Alfabeta: Bandung.

Robbins, Stephen P., Judge, Timothy A. 2016. Perilaku Organisasi Edisi 16. Salemba Empat: Jakarta.

Rivai, V. 2004. Manajemen Sumber Daya Manusia untuk Perusahaan : Dari Teori ke Praktek Rajawali Pers: Jakarta.

Sarwono, Jonathan. (2012). Metode Riset Skripsi Pendekatan Kuantitatif Menggunakan Prosedur SPSS (Edisi Pertama). Jakarta: PT Elex Media Komputindo.

Sardiman A.M. 2012. Interaksi dan Motivasi Belajar Mengajar. Rajawali Press: Jakarta.

Stoner James, A.F. 1996, Manajemen, Edisi Indonesia, Penerbit PT. Prenhallindo: Jakarta

Shalahuddin, Ahmad. 2014. Pengaruh kompensasi dan budaya organisasi terhadap kinerja pegawai dengan motivasi kerja sebagai variabel perantara (studi kasus pada kantor pelayanan pajak pratama 
sintang). Jurnal Manajemen Teori dan Terapan. Tahun \&. No. 1, April 2014

Siagian, Sondang P. 2009. Kiat Meningkatkan Produktivitas Kerja. PT. Rineka Cipta: Jakarta.

Singarimbun. Masri \& Sofyan Effendi, 1995, Metode Penelitian Survei, Edisi Revisi, PT. Pustaka LP3ES, Jakarta

Simamora, H. 2004. Manajemen Sumber Daya Manusia. STIE YKPN: Yogyakarta.

Sudarmanto. 2013. Kinerja dan Pengembangan Kompetensi SDM. Pustaka Pelajar: Yogyakarta.

Sutrisno, E. (2009). Manajemen sumber daya manusia. Kencana: Jakarta. . (2014). Manajemen sumber daya manusia. Kencana: Jakarta.

Sunyoto, Danang. 2015. Manajemen dan Pengembangan Sumber Daya Manusia (Cetakan Pertama). Yogyakarta: CAPS (Center for Academic Publishing Service)

Sanusi, Anwar. 2011. Metodelogi Penelitian Bisnis. Salemba Empat: Jakarta.

Sugiyono. 2013. Metode Penelitian Kualitatif, Kuantitatif, dan $R \& D$. Alvabeta: Bandung. . 2014. Metode Penelitian Kuantitatif Kualitatif dan R\&D. Alfabeta: Bandung.

Susanto, Heri dan Nuraini Aisyah. 2010. Analisis Pengaruh Kepemimpinan dan Budaya Kerja dengan Motivasi sebagai Variabel Intervening terhadap Kinerja Karyawan di Kantor Pertahanan Kabupaten Kebumen. Magistra No. 74 Tahun XXII Desember 2010. ISSN 0215-9511

Schermerhorn. John R., Jamer G. Hut., Richard N. Osborn. 2000. Organizational Behavior. Edisi Ke-6. New York : Jhon Wiley \& Sons, Inc

Uno, Hamzah B., 2008, Orientasi Baru dalam Psikologi Pembelajaran, cetakan kedua, PT Bumi Aksara: Jakarta.

Veithzal Rivai. 2014. Manajemen Sumber Daya Manusia untuk Perusahaan, Edisi ke 6, PT. Raja Grafindo Persada, Depok, 16956.

Wibowo. 2010. Manajemen Kinerja. Rajawali Pers: Jakarta.

2011. Budaya Organisasi:Sebuah Kebutuhan untuk Meningkatkan Kinerja Jangka Panjang. Rajawali Pers: Jakarta.

2012. Manajemen Perubahan, Cetakan Keempat. Rajawali Pers: Jakarta.

Wayne. Dean Mondy dan Joseph J. Martocchio (2016). Human Resource Management (Global Edition). 14th International edition. Pearson Education Limited. United State Of America

Winardi, 2011. Motivasi Pemotivasian dalam manajemen. PT Rajagrafindo Persada: Jakarta.

Wirawan. (2009). Evaluasi Kinerja Sumber Daya Manusia Teori Aplikasi dan Penelitian. Penerbit: Salemba Empat: Jakarta. 